\title{
HPV positive, wild type TP53, and p16 overexpression correlate with the absence of residual tumors after chemoradiotherapy in anal squamous cell carcinoma
}

\author{
Paulo C. Soares ${ }^{1,2^{*}}$, Eliana S. Abdelhay ${ }^{3}$, Luiz Claudio S. Thuler ${ }^{3}$, Bruno Moreira Soares ${ }^{4}$, Samia Demachki ${ }^{5}$, \\ Gessica Valéria Rocha Ferro ${ }^{5}$, Paulo P. Assumpção ${ }^{5}$, Leticia Martins Lamarão ${ }^{6}$, Luis Felipe Ribeiro Pinto ${ }^{3}$ \\ and Rommel Mario Rodríguez Burbano ${ }^{1,4}$
}

\begin{abstract}
Background: Anal residual tumors are consensually identified within six months of chemoradiotherapy and represent a persistent lesion that may have prognostic value for overall survival. The aim of this study was to evaluate the association of HPV and HIV status, p16 expression level and TP53 mutations with the absence of residual tumors (local response) in Squamous Cell Carcinoma (SCC) of the anal canal after chemoradiotherapy.

Methods: We performed a study on 78 patients with SCC of the anal canal who submitted to chemoradiotherapy and were followed for a six-month period to identify the absence or presence of residual tumors. HPV DNA was identified by polymerase chain reaction and direct sequencing, HIV RNA was detected by TaqMan amplification, p16 expression was detected by western blotting, and the mutational analysis of TP53 was performed by direct sequencing; additionally, samples carrying mutations underwent fluorescent in sit hybridization. The evaluation of the tumor response to treatment was conducted six months after the conclusion of chemoradiotherapy. The following classifications were used to evaluate the outcomes: a) no response (presence of residual tumor) and b) complete response (absence of residual tumor).

Results: The significant variables associated with the absence of residual tumors were HPV positive, p16 overexpressed, wild-type TP53, female gender, and stages I and II. Only the presence of HPV was independently correlated with the clinical response; this variable increased the chances of a response within six months by 31 -fold.
\end{abstract}

Conclusions: The presence of HPV in tumor cells was correlated with the absence of a residual tumor. This correlation is valuable and can direct future therapeutic approaches in the anal canal.

Keywords: HPV, HIV, p16, TP53, Anal squamous cell carcinoma

\section{Background}

Squamous cell carcinoma (SCC) of the anal canal has an annual incidence in western countries of 1.0 to 2.5 per 100,000 people, with a female predominance of $2: 1$. It is strongly associated with human papillomavirus (HPV) and human immunodeficiency virus (HIV) infection and

\footnotetext{
* Correspondence: psoares19@hotmail.com

'Hospital Ophir Loyola, Belém, Pará 66060-281, Brazil

Universidade do Estado do Pará, Belém, Pará, Brazil

Full list of author information is available at the end of the article
}

is also significant in immunosuppressed patients following solid organ transplantation [1].

Understanding prognostic biomarkers provides information on how biological factors mediate disease progression and response. The integration of this understanding may allow identification of treatments and facilitate a new therapeutic intervention for all patients with SSC. The use of predictive biomarkers of response may also facilitate the modulation of chemoradiotherapy components and the early detection of relapse, which would facilitate rescue surgery. In addition, there is the potential to 
investigate whether underlying genomic factors modulate the transformation of HPV-induced tumor [2].

Some studies have sought to identify predictive oncobiological factors of local response, disease-free time, and overall survival. Of particular note are the papers that emphasize the role of HPV high-risk genotypes, p16 protein expression and TP53 gene disruption in oropharyngeal and anogenital SCC [3-11]. These studies demonstrate that patients with positive HPV tumors have a better response to standard therapy, as well as those who over-express p16 and do not have a TP53 mutation.

There is still no consensus on the best time to define the lack of clinical response to the treatment of carcinomas. Some prospective studies evaluated the response within 4 weeks after completion of chemoradiation, performing biopsies for pathologic determination within 4 to 6 weeks, rather than longer periods for better evaluation of local tumor regression. An $80 \%$ regression after chemoradiation may predict colostomy-free survival and disease-free survival. Most randomized studies, however, assess the tumor response between 6 and 12 weeks after chemoradiation. Disparities in response rates in several studies may be partially explained by differences in how and when response to treatment was performed [1]. Results from more recent studies show that the proportion of people with a complete clinical response 6 months after initiation of treatment is more strongly associated with progression and mortality compared to any assessment in less time [12].

The current literature concerning local clinical response after treatment indicates that, when there is a suspicion of a residual tumor, digital rectal examination, anoscopy, biopsy, and less frequent imaging techniques, such as endorectal ultrasound, MRI or PET/CT, should always be performed. This is because the most common recurrence sites are near the primary tumour site (75\%), compared to metastatic sites such as presacral, iliac (21\%) and inguinal (4\%) lymph nodes [13, 14].

Even though PET/CT is not a commonly used imaging exam (in the Brazilian public health system) to observe how anal tumors behave, it has been considered an alternative method to evaluate clinical response and disease relapse [15]. A full metabolic response consists of the absence of FDG (2-Deoxy-2-[18F] fluoro-D-glucose) detection in regions where tumors were detected in pre-treatment investigations, while a partial response is defined as an increase or persistence of FDG captations by tumor cells in the same sites. A partial response assessed by post-therapy PET/CT is significantly associated with disease-free survival (22\% versus $95 \%$ ). The elevated negative predictive value (ranging between 94 and $98 \%$ ) of PET/CT is important and avoids unnecessary biopsies or surgeries in patients with irradiated tissue $[13,16]$.
To the best of our knowledge, this type of study has not been conducted in South America. Thus, the objective of this study was to identify the presence of various HPV genotypes, as well as HIV and TP53 mutations, to quantify the p16 expression levels in patients with SCC of the anal canal and to analyze the associations of the variables with local clinical responses to chemoradiotherapy.

\section{Methods}

\section{Clinical data retrieval}

Clinical details were retrieved for 78 patients treated with radical chemoradiotherapy for stages I, II, IIIa and IIIb SCC of the anal canal between 2003 and 2014. The staging was based on the American Joint Committee on Cancer tumor-node-metastasis (TNM) staging system. The treatment used for all patients was the Nigro protocol [17], which consisted of 50.4 Gray of external radiation divided into 28 daily doses and concurrent treatment with 5-flourouracil and mitomycin.

\section{Study design}

- Seventy-eight patients diagnosed with SCC of the anal canal underwent chemoradiation.

- Three months after the end of treatment, all 78 patients made the first evaluation of local response with standard anoscopy, digital rectal examination, and clinical examination of the inguinal region. The objective was to identify if any patient was presenting a lesion progression.

- Six months after the end of treatment, all 78 patients underwent a new evaluation with computer tomography (CT) of the chest, magnetic resonance imaging (MRI) of the abdomen and pelvic, digital rectal examination, high-resolution anoscopy, and clinical examination of the inguinal region. Those who were suspected of a residual lesion underwent a new biopsy to confirm histopathological suspicion of the residual lesion.

- Patients who had residual lesions confirmed by biopsy were referred for surgical treatment.

- The results of the HPV, HIV, TP53 and p16 analyses of all 78 patients were only known after 6 months of treatment (blind to those who evaluated the response and to those who did the molecular analyses).

\section{Analysis of the clinical response}

The evaluation of the tumor response to treatment was conducted six months after the conclusion of chemoradiotherapy for all patients and consisted of chest CT, abdomen and pelvic MRI, digital rectal exam, highresolution anoscopy and clinical examination of the inguinal region. The following classifications were used to evaluate the outcomes: a) no response (presence of 
residual tumor) and b) complete response (absence of residual tumor). Only patients who showed a complete absence of an ulcerative or vegetative lesion were classified as responding. When a suspicious lesion was detected in the anorectal mucosa, biopsy, and histopathology were conducted. All patients followed-up every three and six months.

\section{Pathology review}

Haematoxylin and eosin stained slides of formalin-fixed paraffin-embedded (FFPE) samples were reviewed to confirm the presence of tumors in the blocks. The samples were microdissected by a pathologist and selected for the study.

\section{DNA extraction}

DNA extraction was performed using a QIAGEN (Venlo, Netherlands) QIAamp DNA FFPE Tissue kit.

\section{HPV analysis by direct sequencing}

Samples were submitted to polymerase chain reaction (PCR) using viral gene-specific primers, which amplified a 150 bp fragment of the $L 1$ gene corresponding to a conserved region of the virus genome. After PCR, virus identification was performed by direct sequencing of the PCR product using a capillary sequencer 3730XL DNA Analyzer (Thermo Fisher Scientific, USA).

\section{HIV detection}

Viral RNA was extracted using a QIAGEN (Venlo, Netherlands) QIAamp Viral RNA Mini Kit and transferred to COBAS TaqMan HIV-1 Test, v2.0 (Roche, Pleasanton, $\mathrm{CA})$ for amplification and detection.

\section{TP53 mutation analysis by nucleotide sequencing}

The TP53 gene has 11 exons. Exon 1 is non-coding in the human p53 protein and for this reason was not analyzed in this study. Exons 2-11 of the TP53 gene were separately amplified by PCR using the specific primer sets described in Faria et al. [18] The direct sequencing analysis of the amplified products was performed using the automatic sequencer ABI Prism 3130 (Thermo Fisher Scientific, USA). The resulting sequences were directly edited on the Sequencing Analysis Software on a computer linked to a 3730XL DNA Analyzer (Thermo Fisher Scientific, USA).

\section{Fluorescent in situ hybridization}

Only tumor samples carrying mutations in the TP53 gene were analyzed by fluorescent in situ hybridization (FISH). To determine the chromosome 17 and TP53 copy numbers, the cells were hybridized using a dual-colour direct labelled probe (Abbott/Vysis, USA) specific for the chromosome $17 \alpha$-satellite (SpectrumGreen; p11.1-q11.1) and the TP53 gene region (SpectrumOrange; 17p13.1). Nuclei were counterstained with DAPI/antifade. For each tumor, 200 interphase nuclei were analyzed and scored using the criteria from Hopman et al. [19]

\section{Western blotting}

The analysis was performed as previously described by Leal et al. [20] Reduced protein from each sample was electroblotted onto a polyvinylidene fluoride (PVDF) membrane (GE, USA). The PVDF membrane was blocked and incubated with the primary antibodies: anti-p16 (dilution 1:10; Thermo Fisher Scientific, USA) and anti-ACTB (dilution 1:250; Thermo Fisher Scientific, USA). After washing, a peroxidase-conjugated secondary antibody was added for $1 \mathrm{~h}$ at room temperature. Immunoreactive bands were visualized using the Western blotting Luminol reagent, and the images were acquired using an ImageQuant 350 digital image system (GE, USA). Beta-actin (ACTB) was used as a loading reference control.

\section{Statistical analysis}

This study was a descriptive observational study with a blind laboratory analysis for response to treatment. The mean and standard deviation were calculated for the age variable, and the absolute and relative frequency distributions were calculated for the categorical variables. The association between the independent variables and the presence of a clinical response after six months was analyzed by univariate analysis using Pearson's Chi-square tests or Fisher's exact tests for categorical variables; SPSS version 21.0 (IBM, USA) was used for statistical analysis. To estimate the independent factors associated with a clinical response at 6 months, all the variables with $p$-values $<0.20$ in the univariate analysis were used in the Cox regression. Only variables with $p$-values $<0.05$ were retained in the model.

\section{Results \\ Study population}

The age of the 78 patients with SCC of the anal canal ranged from 34 to 86 years (mean $63.4 \pm 10.3$ ), and 64 patients (82.1\%) were female. Analysis of their clinical stage (TNM) showed that the majority of the patients were stage II $(60.3 \%)$. For the variable $\mathrm{T}$, we found that 30 patients were T2 (38.5\%) and 30 were T3 (38.5\%). Thus, more than $2 / 3(77.0 \%)$ of the patients had tumors classified as T2 or T3. Sixty patients (76.9\%) clinically evaluated by imaging did not have metastases in their lymph nodes (N0), whereas 18 (23.1\%) were positive for lymph node metastases. Analysis of the degree of cellular differentiation showed a predominance of grade II (74.4\%). HIV was detected in 18 of the investigated biopsies $(23,07 \%)$. Nine $(64.28 \%)$ males and $9(14.06 \%)$ females were HIV positive. 
HPV was detected in 59 of the analyzed biopsies (75.6\%). HPV 16 was most common and was detected in $49(62.8 \%)$ tumors, followed by HPV 18 in 10 (12.8\%) tumors. Nineteen patients $(24.4 \%)$ did not have detectable HPV infections, and no other type of HPV was found.

Overexpression of p16 was found in 57 patients (73.1\%). Overexpression was defined as 50\% higher expression of the protein in the tumor tissue than in the normal anal mucosal tissues used as the control. Overexpression was not detected in 19 patients $(24.4 \%)$ because the amount of protein detected in the tumour was $49 \%$ or less compared to the control. Borderline overexpression was found in two patients $(2.6 \%)$ because protein expression in the tumor was $47 \%$ and $50 \%$ more than the control.

Analysis of the clinical response at six months showed a complete response in 47 patients (60.3\%), and a residual tumor detectable by clinical exam and confirmed by histopathological analysis was found in 31 (39.7\%) patients.

\section{Mutational status and TP53 copy number and $\mathrm{p} 16$ protein expression analyses}

TP53 was wild type in 57 patients $(73.1 \%)$ and mutated in $21(26.9 \%)$ patients. All cases with p16 overexpression had wild-type TP53 (73.1\%) and vice versa. All the patient characteristics studied are shown in Table 1.

Of the 78 patients analyzed, 21 had mutations in exons 5, 6, 7 or 8 of the TP53 gene. All the mutations identified were homozygous and consisted of both non-functional (80.5\%) and partially functional (19.05\%) variants (Fig. 1). Because the homozygous state of the mutations may be due to a loss of one allele, cases with mutations in TP53 were analyzed for copy number by FISH (Table 2).

Aneuploidies in chromosome 17, where the TP53 gene is located, were analyzed to establish a relationship between the number of TP53 alleles and the number of chromosome 17 copies. Table 2 shows that two chromosome 17 copies and a single allele of the TP53 gene (2/1) were present between $49.5 \%$ and $15 \%$ of the cells in cases 50 (Fig. 2) and 60, respectively.

Several other changes were also observed in this analysis (Table 2), including the presence of only one chromosome 17 and one allele of the TP53 gene (1/1) between $1.5 \%$ and $10,5 \%$ of the cells in cases 29 and 57, respectively. Additional changes, such as three chromosome 17 copies and two alleles of the TP53 gene (3/2) and other combinations, were observed in small cellular clones.

Another phenomenon worth highlighting is that $90 \%$ of the mutations in the TP53 gene occurred in tumors that were both HPV negative and did not overexpress the p16 protein, whereas the other $10 \%$ occurred in tumors testing positive for HPV and containing borderline overexpression of this protein.

\section{Factors correlated to the clinical response}

The variables with significant associations with the clinical response were HPV, p16, TP53, female gender, and stage I or II cancer. Therefore, HPV was highly associated with patients with a complete response to chemotherapy (absence of a residual tumor), with a $p$-value < 0.001 . HPV positive tumors showed p16 overexpression $79.7 \%$ of the time ( $p$-value $=0.003$ ), had borderline overexpression $2.7 \%$ of the time and were under expressed $24.4 \%$ of the time. Figure 3 shows a representative western blot of p16. The TP53 gene was wild type in $78.9 \%$ ( $p$-value $=0.003)$ of the tumors positive for HPV (Tables 3 and 4 ).

After adjusting for variables with a $p$-value $<0.20$ in the univariate analysis (Table 4), only the presence of HPV was independently correlated with the clinical response. This variable increased the chances of a response within six months by 31 -fold.

\section{Discussion}

Tumors affecting the anal canal generally regress slowly after chemoradiotherapy [21]. Favorable clinical outcome at three months seems to be more important than the initial $\mathrm{T}$ and $\mathrm{N}$ stages, and the magnitude of tumor regression (over $80 \%$ ) is a better predictor of both colostomy and disease-free survival [22]. In our study, we observed that the female gender $(p=0.022)$ and clinical stages I and II $(p=0.008)$ were predictive variables for a good local response and significantly increased the chances of responding to treatment compared to males and the more advanced stages III A and III B. In our analysis, tumor size and lymph node metastases were not identified as independent predictive variables.

The evaluation of complete response after six months of chemoradiotherapy and the correlation with the biomarkers analyzed in this study is a significant parameter, but it is not definitive. A 3-year locoregional control rate would be considered the most relevant evaluation because it provides information on recurrences (local and distant), which occur predominantly in the first year after treatment [23]. We did not follow-up for three years because most of the patients who participated in this study did not return to the hospital after the six-month visit.

HPV status is recognized as prognostic factor in head and neck carcinomas, where it is agreed that positive $\mathrm{HPV}$ patients react well to chemoradiotherapy. Interest in identifying the role of HPV in SCC of the anal canal has increased because patients with HPV positive tumors in the head and neck region, especially the oropharyngeal region, have better overall survival. Thus, the role of high risk HPV in the aetiology of SCC of the anal canal is well established [4, 5, 21, 24-29]. 
Table 1 Patient characteristics

\begin{tabular}{|c|c|c|c|c|c|}
\hline Characteristics & $N$ & $\%$ & $\begin{array}{l}\text { HPV Positive } \\
N(\%)\end{array}$ & $\begin{array}{l}\text { HPV Negative } \\
N(\%)\end{array}$ & $p$-value \\
\hline Age & & & & & 0.361 \\
\hline$<65$ years old & 44 & $56.4 \%$ & & & \\
\hline$\geq 65$ years old & 34 & $43.6 \%$ & $35(59.3)$ & $9(47.4)$ & \\
\hline Gender & & & $24(40.7)$ & $10(52.6)$ & 0.004 \\
\hline Female & 64 & 82.1 & & & \\
\hline Male & 14 & 17.9 & $53(89.8)$ & $11(57.9)$ & \\
\hline Degree of Cellular Differentiation & & & $6(10.2)$ & $8(42.1)$ & 0.351 \\
\hline GI & 6 & 7.7 & & & \\
\hline$G \|$ & 58 & 74.4 & $6(10.2)$ & $0(0)$ & \\
\hline G III & 11 & 14.1 & $42(71.2)$ & $16(84.2)$ & \\
\hline GIV & 3 & 3.8 & $8(13.6)$ & $3(15.8)$ & \\
\hline Clinical Stage (UICC) & & & $3(5.1)$ & $0(0)$ & 0.031 \\
\hline । & 5 & 6.4 & & & \\
\hline$\|$ & 47 & 60.3 & $5(8.5)$ & $0(0)$ & \\
\hline IIIA & 16 & 20.5 & $39(66.1)$ & $8(42.1)$ & \\
\hline$\| \mathrm{B}$ & 10 & 12.8 & $8(13.6)$ & $8(42.1)$ & \\
\hline N Stage & & & $7(11.9)$ & $3(15.8)$ & 0.354 \\
\hline Negative & 60 & 76.9 & & & \\
\hline Positive & 18 & 23.1 & $47(79.7)$ & $13(68.4)$ & \\
\hline T Stage & & & $12(20.3)$ & $6(31.6)$ & 0,012 \\
\hline $\mathrm{T} 1(\leq 2 \mathrm{~cm})$ & 6 & 7.7 & & & \\
\hline $\mathrm{T} 2(>2$ and $\leq 5 \mathrm{~cm})$ & 30 & 38.5 & $6(10.2)$ & $0(0)$ & \\
\hline $\mathrm{T} 3(>5 \mathrm{~cm})$ & 30 & 38.5 & $27(45.8)$ & $3(15.8)$ & \\
\hline T4 (tumour invading adjacent organ) & 12 & 15.4 & $20(33.9)$ & $10(52.6)$ & \\
\hline HPV & & & $6(10.2)$ & $6(31.6)$ & NA \\
\hline 16 & 49 & 62.8 & & & \\
\hline 18 & 10 & 12.8 & 49 (62.8) & $0(0)$ & \\
\hline Negative & 19 & 24.4 & $10(12.8)$ & $0(0)$ & \\
\hline HIV & & & $19(24.4)$ & $0(0)$ & 1.000 \\
\hline Positive & 19 & 24.4 & & & \\
\hline Negative & 59 & 75.6 & $14(23.7)$ & $5(26.3)$ & \\
\hline P16 & & & $45(76.3)$ & $14(73.7)$ & $<0.001$ \\
\hline Positive & 57 & 73.1 & & & \\
\hline Negative & 19 & 24.4 & $57(96.6)$ & $0(0)$ & \\
\hline Borderline & 2 & 2.6 & $0(0)$ & $19(100.0)$ & \\
\hline Clinical response at 6 months & & & $2(3.4)$ & $0(0)$ & $<0.001$ \\
\hline Yes & 47 & 60.3 & & & \\
\hline No & 31 & 39.7 & $47(79.7)$ & $0(0)$ & \\
\hline TP53 & & & $12(20.3)$ & $19(100.0)$ & $<0.001$ \\
\hline Mutated & 21 & 26.9 & & & \\
\hline Wild type & 57 & 73.1 & $2(3.4)$ & $19(100.0)$ & \\
\hline Total & 78 & 100.0 & $57(96.6)$ & $0(0)$ & \\
\hline
\end{tabular}

$N A=$ Not available

Statistically significant $p$-values are shown in bold 


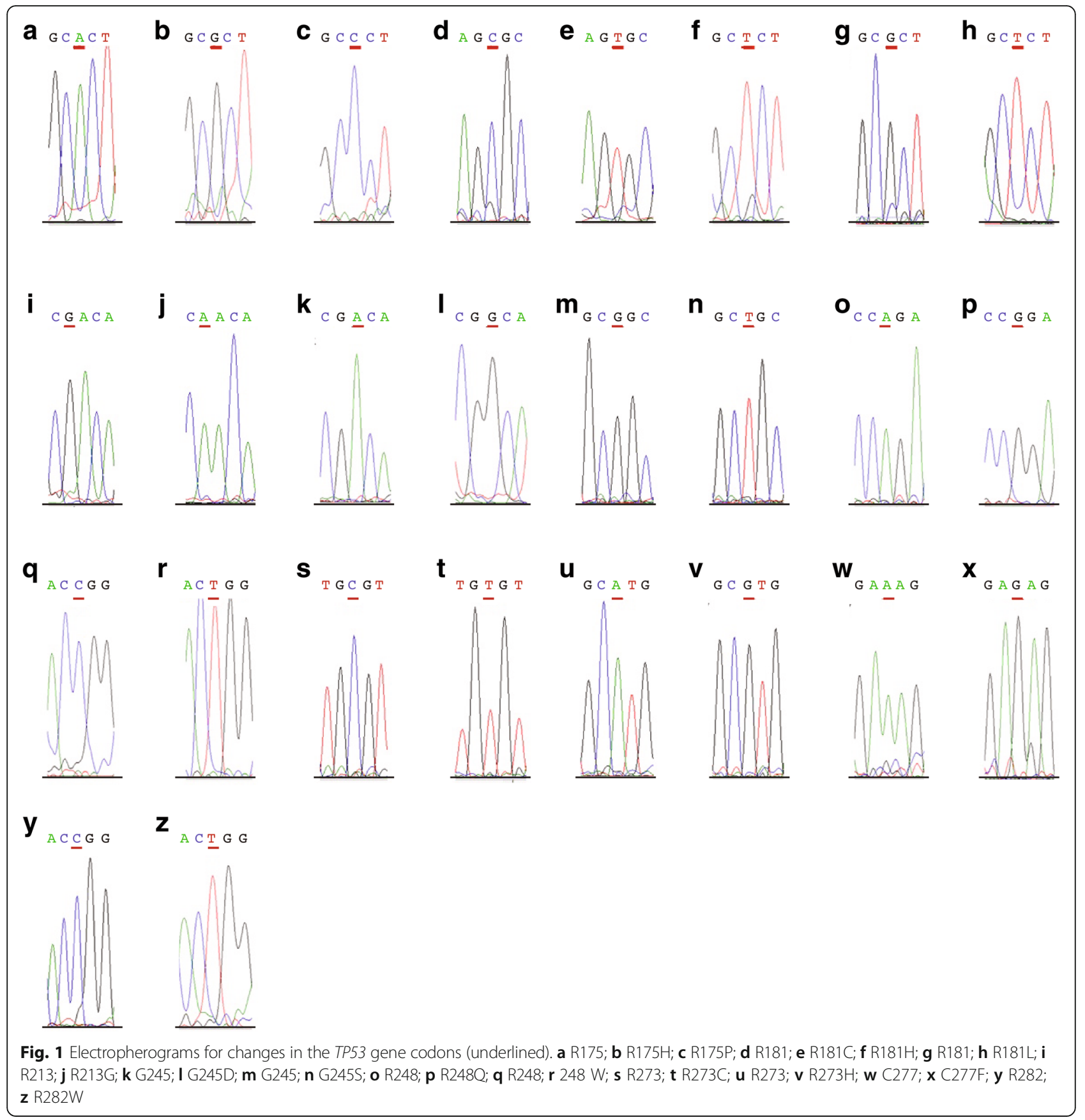

A complete clinical response, i.e. the absence of residual tumour after six months of the end of treatment with chemoradiation, is considered an excellent predictor of local control. In fact, several studies have shown that after this period, an $80 \%$ regression in $\mathrm{T} 3$ and $\mathrm{T} 4 \mathrm{tu}-$ mors is predictive of disease-free survival in two years: $66 \%$ versus $20 \%$ for responders and non-responders, respectively $[22,28]$.

In this study, the presence of HPV increased the chance of absence of residual tumors, within six months, by 31 -fold. HPV was detected in $75.6 \%$ of the biopsies; of these, $79.7 \%$ ( $p=0.018)$ showed complete local regression, and $20.3 \%$ had residual tumors after six months. However, all the patients with HPV negative biopsies (24.4\%) had residual tumors, which is higher than expected when compared to data published in international studies $[6,7,10,11,30]$. All patients who had detectable residual lesions underwent a CT of the chest and MRI of their abdomen and pelvis to analyze the distant metastasis and regional lymph node chains.

In a retrospective study, Yhim et al. found similar results. They analyzed the prognostic significance of HPV 
Table 2 Mutational status and copy number analysis for the TP53 gene and quantification of the centromeres of chromosome 17 in anal canal tumours according to HPV infection status and p16 expression

\begin{tabular}{|c|c|c|c|c|c|c|c|c|c|c|c|}
\hline \multicolumn{4}{|c|}{ HPV negative /p16 negative } & \multicolumn{8}{|c|}{ FISH chromosome 17/ gene TP53 (\%) } \\
\hline Case & Protein Change & Functional Consequence & Exon & $2 / 2$ & $2 / 1$ & $1 / 1$ & $3 / 2$ & $3 / 1$ & $3 / 3$ & $4 / 2$ & $4 / 1$ \\
\hline 6 & $\mathrm{R} 282 \mathrm{~W}$ & Non-functional & 8 & 60.5 & 28.0 & 10.0 & 1.5 & - & - & - & - \\
\hline 7 & R181L & Partially functional & 5 & 52.5 & 43.0 & 4.5 & - & - & - & - & - \\
\hline 11 & $\mathrm{R} 273 \mathrm{H}$ & Non-functional & 8 & 69.0 & 23.0 & 4.5 & 3.5 & - & - & - & - \\
\hline 16 & G245S & Non-functional & 7 & 67.5 & 28.5 & 2.0 & 2.0 & - & - & - & - \\
\hline 19 & $\mathrm{R} 273 \mathrm{H}$ & Non-functional & 8 & 70.0 & 24.5 & 4.0 & 1.5 & - & - & - & - \\
\hline 23 & $\mathrm{R} 175 \mathrm{P}$ & Non-functional & 5 & 72.0 & 20.0 & 6.0 & 2.0 & & & - & - \\
\hline 31 & $\mathrm{R} 175 \mathrm{H}$ & Non-functional & 5 & 67.0 & 23.0 & 7.0 & 3.0 & - & - & - & - \\
\hline 34 & G245D & Non-functional & 7 & 64.5 & 20.5 & 10.0 & 3.0 & 2.0 & - & - & - \\
\hline 49 & R181C & Partially functional & 5 & 48.0 & 44.0 & 8.0 & - & - & - & - & - \\
\hline 50 & $\mathrm{R} 181 \mathrm{H}$ & Partially functional & 5 & 44.5 & 49.5 & 6.0 & - & - & - & - & - \\
\hline 59 & R213Q & Non-functional & 6 & 64.0 & 26.0 & 6.5 & 3.5 & - & - & - & - \\
\hline 60 & R248W & Non-functional & 7 & 76.5 & 15.0 & 7.5 & 0.5 & 0.5 & - & - & - \\
\hline 63 & $\mathrm{R} 175 \mathrm{H}$ & Non-functional & 5 & 68.0 & 22.5 & 5.5 & 4.0 & - & - & - & - \\
\hline 64 & $\mathrm{C} 277 \mathrm{~F}$ & Non-functional & 8 & 63.4 & 17.0 & 8.0 & 4.2 & 4.2 & 1.6 & 1.6 & - \\
\hline 70 & R273C & Non-functional & 8 & 63.0 & 19.0 & 7.5 & 7.5 & 2.0 & 1.0 & - & - \\
\hline 72 & $\mathrm{R} 248 \mathrm{Q}$ & Non-functional & 7 & 65.0 & 17.5 & 9.5 & 4.0 & 1.5 & 1.5 & 1.0 & - \\
\hline 75 & $\mathrm{R} 248 \mathrm{Q}$ & Non-functional & 7 & 67.0 & 18.5 & 7.5 & 3.0 & 1.5 & 1.5 & 1.0 & - \\
\hline 76 & R213Q & Non-functional & 6 & 65.0 & 25.5 & 5.5 & 4.0 & - & - & - & - \\
\hline 77 & $\mathrm{R} 273 \mathrm{C}$ & Non-functional & 8 & 62.7 & 24.3 & 2.7 & 5.5 & 2.7 & 1.6 & 0.5 & - \\
\hline \multicolumn{4}{|c|}{ HPV positive/p16 borderline } & $2 / 2$ & $2 / 1$ & $1 / 1$ & $3 / 2$ & $3 / 1$ & $3 / 3$ & $4 / 2$ & $4 / 1$ \\
\hline 29 & G245S & Non-functional & 7 & 54.0 & 24.0 & 1.5 & 5.0 & 5.5 & 2.5 & 6.0 & 1.5 \\
\hline 57 & $\mathrm{R} 181 \mathrm{H}$ & Partially functional & 5 & 59.0 & 23.0 & 10.5 & 1.5 & 2.0 & 1.0 & 1.5 & 1.5 \\
\hline
\end{tabular}

type 16 after an oncological follow-up of 51.7 months in patients with SCC of the anal canal treated with chemoradiation and found a disease progression-free period in $63.1 \%$ of the HPV positive patients compared to $15.6 \%$ of the HPV-negative patients and an overall survival of $84.6 \%$ versus $39.8 \%$, respectively [6].

Other studies have also analyzed HPV and p16 expression as markers of the prognostic outcome in patients with SCC of the anal canal and corroborated the results found in this study. Koerber et al. analyzed the HPV and p16 statuses in 105 patients with SCC of the anal canal in a study cohort. The average follow-up was 48.6 months, and the analysis showed that the overall survival and progression-free times were three years longer in the HPV positive patients than in the HPV-negative patients. The authors also concluded that HPV detection and p16 expression together represented a prognostic marker in patients with SCC of the anal canal [8]. Mai et al. conducted a study that analyzed the prognostic relevance of HPV combined with p16 expression and observed that locoregional clinical control was significantly higher in stage T1/T2, female, HPV positive, and p16overexpressing patients [9].
Meulendijks et al. performed a cohort study in 107 patients with SCC of the anal canal undergoing standard treatments. They demonstrated that the HPV and p16 statuses were strong predictors of locoregional clinical control and overall survival. The outcomes of patients with HPV negative/non-p16-overexpressing tumors were considerably worse than those of patients with HPV positive/p16-overexpressing tumors. Similar to our study, they found a high frequency of p53 mutations in the HPV negative/non-p16-overexpressing tumors (80\%) and a sporadic frequency in the HPV positive/p16-overexpressing tumors (6\%) [10]. However, unlike our results, they observed that 4 of the 16 HPV negative tumors had p16 overexpression (25\%). Similarly, in a population of 135 patients, Serup-Hansen et al. found that 6 out of $15 \mathrm{HPV}$ negative tumors (40\%) showed overexpression of the p16 protein [30].

TP53 sequence analysis of the 78 tumor samples showed that 21 patients had tumors with homozygous mutations in this gene (Table 2). Therefore, the copy number analysis by FISH was performed on TP53 mutations to verify whether the mechanism of the loss of heterozygosity $(\mathrm{LOH})$ was involved in the carcinogenicity of 


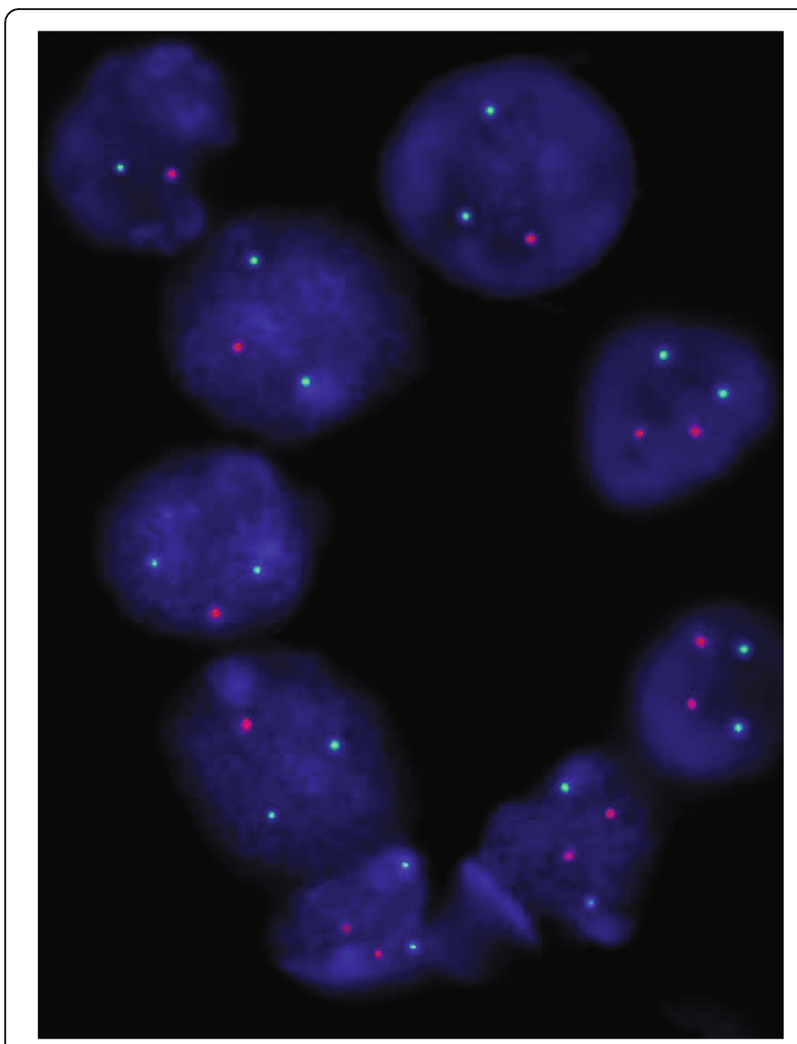

Fig. 2 Interphase nuclei from SCC of anal canal cells after FISH analysis. Green points correspond to centromeres of chromosome 17, and red points correspond to alleles of the TP53 gene the anus, i.e. to confirm whether the mutation is homozygous. This was visualized by the Sanger sequencing method, to determine if it originated from the two mutated alleles or because only one allele was sequenced since the other allele was lost by deletion and gave the false impression of homozygous [31, 32].
The FISH analysis (Table 2) revealed the presence of two chromosome 17 copies and a single allele of the TP53 gene (2/1) in $15 \%$ to $49.5 \%$ of the analyzed tumor cells, indicating that $\mathrm{LOH}$ is a mechanism for the activation of this tumour suppressor gene. Another population of cells with homozygous mutations in the TP53 gene that could be explained by a similar mechanism was the clone with only one chromosome 17 and one allele of the TP53 gene (1/1) that was found in $1.5 \%$ to $10.5 \%$ of the cells in the analyzed samples.

Additionally, the typical diploid ratio of normal somatic human cells was also observed in $44.5 \%$ to $76.5 \%$ of the cells in the 21 analyzed cases. For these cellular clones, which represent most of the cells in the tumor, there are two other mechanisms to explain the homozygosity of the mutations. The first explanation is the occurrence of sporadic mutations in the two alleles of the tumor cells, and the second is gene conversion [33].

Other changes, such as the presence of three chromosome 17 copies and two TP53 alleles (3/2) and other combinations, were observed in small clones of cells. These homozygous mutations can also be explained by the two mechanisms cited above.

Another significant phenomenon is that $100 \%$ of the HPV negative tumours had mutations in the TP53 gene. This change in the genome of the anal mucosal cells could cause the formation of the tumor because the loss of p53 suppression might be directly related to carcinogenesis in some types of cancer [34].

TP53 mutations may explain the process of carcinogenesis in the anal canal in $3.4 \%$ of the HPV positive tumors. Additionally, the mechanism of carcinogenesis might be related to the dysregulation of TP53 by the viral oncogene E6 in the $96.6 \%$ of the tumors that were HPV positive but did not have mutations in this gene [35].

The SCC model of the anal canal may also explain why the presence of the virus gives a better response to

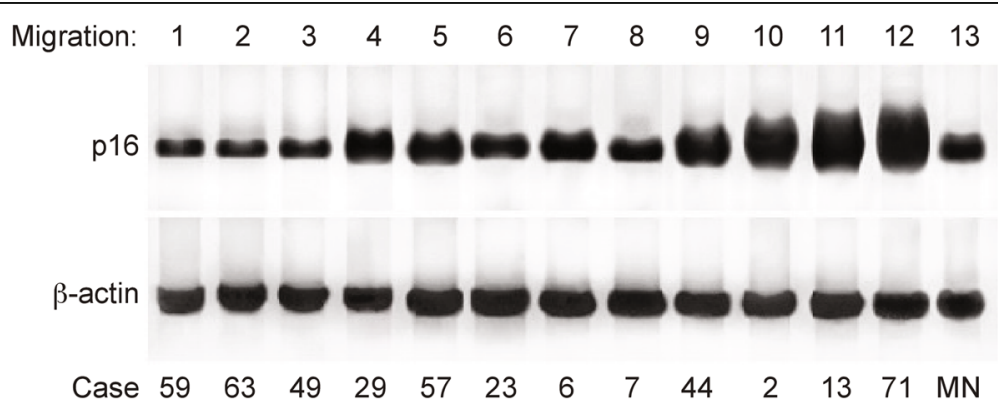

Fig. 3 Representative western blot of p16 (upper gel) and beta-actin (lower gel), which was used as an endogenous marker for normalization. Lanes are labelled at the top of the figure, and the case numbers for the patients analyzed are labelled at the bottom. Lanes 1-3 correspond to cases with mutations in TP53 that are negative for the HPV virus and p16 overexpression. Lanes 4 and 5 correspond to HPV positive cases with mutated TP53 and borderline p16 overexpression. Lanes 6, 7 and 8 correspond to cases with mutated TP53 that are negative for HPV and do not overexpress p16 (p16 expression similar to the normal anal mucosa tissue). Lanes 9-12 corresponded to samples with wild-type TP53 that are positive for HPV and exhibit p16 overexpression. Line 13 corresponds to a pool of p16 proteins extracted from five normal anal mucosal (NM) tissues 
Table 3 Presence of a clinical response at 6 months by selected factors

\begin{tabular}{|c|c|c|c|}
\hline Characteristics & $\begin{array}{l}\text { Clinical } \\
\text { response (\%) }\end{array}$ & $\begin{array}{l}\text { No clinical } \\
\text { response (\%) }\end{array}$ & $p$-value \\
\hline Age & & & 0.488 \\
\hline$<65$ years old & $28(63.6)$ & $16(36.4)$ & \\
\hline$\geq 65$ years old & $19(55.9)$ & $15(44.1)$ & \\
\hline Gender & & & $<0.001$ \\
\hline Female & $46(71.9)$ & $18(28.1)$ & \\
\hline Male & $1(7.1)$ & $13(92.9)$ & \\
\hline Degree of Cell Differentiation & & & 0.387 \\
\hline$G \mid / G \|$ & $40(62.5)$ & $24(37.5)$ & \\
\hline GIII/G IV & $7(50.0)$ & $7(50.0)$ & \\
\hline Clinical Stage (UICC) & & & $<0.001$ \\
\hline I- II & $31(86.1)$ & $5(13.9)$ & \\
\hline$\| I|A-||| B$ & $16(38.1)$ & $26(61.9)$ & \\
\hline T stage & & & $<0.001$ \\
\hline $\mathrm{T} 1(\leq 2 \mathrm{~cm})$ & $1(16.7)$ & $5(83.3)$ & \\
\hline T 2 (> 2 and $\leq 5 \mathrm{~cm})$ & $4(13.3)$ & $26(86.7)$ & \\
\hline T3 $(>5 \mathrm{~cm})$ & $15(50.0)$ & $15(50.0)$ & \\
\hline $\begin{array}{l}\text { T } 4 \text { (tumour invading } \\
\text { adjacent organ) }\end{array}$ & $11(91.7)$ & $1(8.3)$ & \\
\hline N stage & & & 0.035 \\
\hline Negative & $40(66.7)$ & $20(33.3)$ & \\
\hline Positive & $7(38.9)$ & $11(61.1)$ & \\
\hline HPV & & & $<0.001$ \\
\hline Positive & $47(79.7)$ & $12(20.3)$ & \\
\hline Negative & $0(0.0)$ & $19(100.0)$ & \\
\hline HIV & & & 0.063 \\
\hline Positive & $8(42.1)$ & $11(57.9)$ & \\
\hline Negative & $39(66.1)$ & $20(33.9)$ & \\
\hline P16 & & & $<0.001$ \\
\hline Positive & 45 (78.9) & $12(21.1)$ & \\
\hline Negative/borderline & $2(9.5)$ & $19(90.5)$ & \\
\hline TP53 & & & $<0.001$ \\
\hline Mutant & $2(9.5)$ & $19(90.5)$ & \\
\hline Wild type & 45 (78.9) & $12(21.1)$ & \\
\hline
\end{tabular}

Statistically significant $p$-values are shown in bold

therapy across the spectrum of HPV associated tumors (oropharynx, cervix, vulva, penis) [2]. The presence of TP53 mutations is associated with worse outcomes after chemoradiotherapy and is inversely correlated with the presence of p16 / HPV [7]. Mutations of TP53 and HPV involvement are, for the most part, mutually exclusive in SCC of the anal canal [10] and in head and neck cancer [36]. HPV positive tumors develop through the production of the E6 oncoprotein and chemoradiotherapy can disrupt this process causing significant DNA damage. In
Table 4 Univariate and multiple analyses of factors associated with the clinical response at 6 months

\begin{tabular}{lllllll}
\hline Characteristics & OR & $95 \% \mathrm{Cl}$ & $p$ & aOR & $95 \% \mathrm{Cl}$ & $p$ \\
\hline HPV positive & 31.1 & $1.8-531.1$ & $\mathbf{0 . 0 1 8}$ & 31.1 & $1.8-531.1$ & $\mathbf{0 . 0 1 8}$ \\
Female gender & 10.1 & $1.4-73.0$ & $\mathbf{0 . 0 2 2}$ & & & \\
P16 positive & 8.3 & $2.0-34.2$ & $\mathbf{0 . 0 0 3}$ & & & \\
Age $<65$ years & 1.1 & $0.6-2.0$ & 0.662 & & & \\
$\begin{array}{l}\text { Degree of cell } \\
\text { differentiation }\end{array}$ & 1.3 & $0.6-2.5$ & 0.586 & & \\
I and II & & & & & \\
Clinical stage & 2.5 & $1.3-5.0$ & $\mathbf{0 . 0 0 8}$ & & \\
I and II & & & & & \\
T 2/3 & 1.2 & $0.5-3.1$ & 0.675 & & \\
TP53 mutated & 0.1 & $0.03-0.5$ & $\mathbf{0 . 0 0 3}$ & \\
\hline $\begin{array}{l}\text { OR = Odds ratio; aOR }=\text { Adjusted odds ratio } \\
\text { Statistically significant } p \text {-values are shown in bold }\end{array}$
\end{tabular}

the absence of E6 (i.e., HPV negative cases), the TP53 mutation is irreversible and the DNA-damage-response (DDR) mechanisms are no longer orchestrated by the p53 protein, which can cause increasingly aberrant cells after treatment $[2,37]$.

The difference between these two mechanisms to inactivate the activity of the p53 protein may explain why HPV negative patients generally do not respond to treatment within 6 months. Our hypothesis proposes that the mutations in TP53 found in the tumor cells of HPV negative patients produce abnormal proteins that confer chemoresistance to the administered treatment. Conversely, the majority of HPV positive tumors (79.7\%) responded well to chemotherapy, which is explained under our hypothesis by their production of wild-type p53; even though p53 was degraded by the viral E6 oncoprotein, other proteins were concurrently generated to maintain a basal level of the protein that likely prevented the onset of chemoresistance.

Patients with SCC anal canal tumors with mutations of TP53 gene are associated with short-term disease-free survival and decreased local responses [3, 38-42]. These observations are consistent with our results, where a significant majority of the mutant TP53 tumors did not show a local response, although we did not analyze disease-free survival.

Individuals infected with HIV are at increased risk of infection with both low-risk and high-risk HPV types. Chronic immunosuppression provides an environment for persistent HPV infection which carries a higher risk of malignant transformation [43]. In this study, HIV infection was not associated with the presence of HPV and/or clinical response in SCC, reinforcing the hypothesis that HPV infection is only one of the mechanisms of anal canal carcinogenesis.

The explanation for the favorable clinical outcome of chemoradiotherapy in HPV16 positive patients is evident 
in tumors harboring strong infiltration of immune cells. These tumors present tumor-infiltrating lymphocytes (TILs) with a strong expression of CD8 and the immunological markers Programmed Cell Death Protein-1 (PD-1) and its ligand (PD-L1) [44, 45] Patients with SSC of the anal canal with high levels of infiltration of TILs present a relapse-free rate higher than those with low levels of infiltration of TILs [46]. For this reason it is important that the immune recognition in SSC of the anal canal is measured systemically.

\section{Conclusions}

Only the presence of HPV increased the chance of absence of residual tumors, within six months, by 31 -fold. This correlation is valuable and can direct future therapeutic approaches in SCC of the anal canal.

\section{Abbreviations}

ACTB: Beta-actin; CMT: Combined Modality Therapy; CT: Computer Tomography; FDG: 2-Deoxy-2-[18F] fluoro-D-glucose; FFPE: Formalin-Fixed Paraffin-Embedded; FISH: Fluorescent In Situ Hybridization; HIV: Human Immunodeficiency Virus; HOL: Hospital Ophir Loyola; HPV: Human Papillomavirus; MRI: Magnetic Resonance Imaging; NM: Normal Anal Mucosal; PCR: Polymerase Chain Reaction; PET/CT: Positron Emission Tomography-Computed Tomography; PVDF: Polyvinylidene Fluoride; SCC: Squamous Cell Carcinoma; TNM: Cancer Tumour-Node-Metastasis

\section{Acknowledgements}

The authors thank all patients who participated in the study. We thank all laboratory personnel working at the Laboratório de Biologia Molecular do Hospital Ophir Loyola and the support of PROPESP / UFPA.

\section{Funding}

Funding for this study was provided as grants and fellowships from the Hospital Ophir Loyola (to PCS and RRB) and the Conselho Nacional de Desenvolvimento Científico e Tecnológico (to RRB \# 305220/2013-6). The institutions and granters had no role in the study design, data collection and analysis, decision to publish, or preparation of the manuscript.

\section{Availability of data and materials}

All experimental data and analysis results were stored in the laboratory molecular biology computer and all tissue slides were stored in the Ophir Loyola Hospital, which are available to be reviewed. No public database is available to deposit our data. The datasets used and/or analyzed during the current study are available from the corresponding author on reasonable request.

\section{Authors' contributions \\ PCS, LCST, PPA and LFRP conceived and designed the study. PCS, BMS, SD, GVRF, LFRP and LML conducted the study and participated in the laboratory analysis. PCS, BMS, SD, GVRF, LCST, ESFW, and RRB analyzed the data. PCS, BMS, LCST, LFRP, ESFW and RRB wrote the paper. All authors read and approved the final manuscript.}

\section{Ethics approval and consent to participate}

This work was granted ethical approval by the Hospital Ophir Loyola Committee (HOL 72710/12). A Free and Informed Consent Form was read and signed by patients who participated in this study.

\section{Consent for publication}

Not applicable.

\section{Competing interests}

The authors declare that they have no competing interests.

\section{Publisher's Note}

Springer Nature remains neutral with regard to jurisdictional claims in published maps and institutional affiliations.

\section{Author details}

${ }^{1}$ Hospital Ophir Loyola, Belém, Pará 66060-281, Brazil. ²Universidade do Estado do Pará, Belém, Pará, Brazil. ${ }^{3}$ Instituto Nacional de Câncer, Rio de Janeiro, Brazil. ${ }^{4}$ Laboratório de Citogenética Humana, Instituto de Ciências Biológicas, Belém, Pará, Brazil. ${ }^{5}$ Núcleo de Pesquisas em Oncologia, Universidade Federal do Pará, Belém, Pará, Brazil. ${ }^{6}$ Fundação de Hematologia e Hemoterapia do Pará, Belém, Pará, Brazil.

Received: 17 March 2017 Accepted: 13 February 2018

Published online: 21 February 2018

References

1. Glynne-Jones R, Renehan A. Current treatment of anal squamous cell carcinoma. Hematol Oncol Clin North Am. 2012;26:1315-50.

2. Jones CM, Goh V, Sebag-Montefiore D, Gilbert DC. Biomarkers in anal cancer: from biological understanding to stratified treatment. Br J Cancer. 2017;116:156-62.

3. Lampejo T, Kavanagh D, Clark J, Goldin R, Osborn M, Ziprin P, Cleator S. Prognostic biomarkers in squamous cell carcinoma of the anus: a systematic review. Br J Cancer. 2010;103:1858-69.

4. Ang KK, Harris J, Wheeler R, Weber R, Rosenthal DI, Nguyen-Tân PF, Westra WH, Chung $\mathrm{CH}$, Jordan RC, Lu C, Kim H, Axelrod R, Silverman CC, Redmond KP, Gillison ML. Human papillomavirus and survival of patients with oropharyngeal cancer. N Engl J Med. 2010;363:24-35.

5. Rischin D, Young RJ, Fisher R, Fox SB, Le QT, Peters LJ, Solomon B, Choi J, O'Sullivan B, Kenny LM, McArthur GA. Prognostic significance of p16INK4A and human papillomavirus in patients with oropharyngeal cancer treated on TROG 02.02 phase III trial. J Clin Oncol. 2010;28:4142-8.

6. Yhim HY, Lee NR, Song EK, Kwak JY, Lee ST, Kim JH, Kim JS, Park HS, Chung IJ, Shim HJ, Hwang JE, Kim HR, Nam TK, Park MR, Shim H, Park HS, Kim HS, Yim CY. The prognostic significance of tumor human papillomavirus status for patients with anal squamous cell carcinoma treated with combined chemoradiotherapy. Int J Cancer. 2011;129:1752-60.

7. Gilbert DC, Williams A, Allan K, Stokoe J, Jackson T, Linsdall S, Bailey CM, Summers J. p16INK4A, p53, EGFR expression and KRAS mutation status in squamous cell cancers of the anus: correlation with outcomes following chemo-radiotherapy. Radiother Oncol. 2013;109:146-51.

8. Koerber SA, Schoneweg C, Slynko A, Krug D, Haefner MF, Herfarth K, Debus J, Sterzing F, von Knebel Doeberitz M, Prigge ES, Reuschenbach M. Influence of human papillomavirus and p16(INK4a) on treatment outcome of patients with anal cancer. Radiother Oncol. 2014;113:331-6.

9. Mai S, Welzel G, Ottstadt M, Lohr F, Severa S, Prigge ES, Wentzensen N, Trunk MJ, Wenz F, von Knebel-Doeberitz M, Reuschenbach M. Prognostic relevance of HPV infection and p16 overexpression in squamous cell anal cancer. Int J Radiat Oncol Biol Phys. 2015;93:819-27.

10. Meulendijks D, Tomasoa NB, Dewit L, Smits PH, Bakker R, van Velthuysen ML, Rosenberg EH, Beijnen JH, Schellens JH, Cats A. HPV-negative squamous cell carcinoma of the anal canal is unresponsive to standard treatment and frequently carries disruptive mutations in TP53. Br J Cancer. 2015;112:1358-66.

11. Rödel F, Wieland U, Fraunholz I, Kitz J, Rave-Fränk M, Wolff HA, Weiss C, Wirtz R, Balermpas P, Fokas E, Rödel C. Human papillomavirus DNA load and p16INK4a expression predict for local control in patients with anal squamous cell carcinoma treated with chemoradiotherapy. Int J Cancer. 2015;136:278-88.

12. Glynne-Jones R, Sebag-Montefiore D, Meadows HM, Cunningham D, Begum R, Adab F, Benstead K, Harte RJ, Stewart J, Beare S, Hackshaw A, Kadalayil L. ACT II study group. Best time to assess complete clinical response after chemoradiotherapy in squamous cell carcinoma of theanus (ACT II): a post-hoc analysis of randomised controlled phase 3 trial. Lancet Oncol. 2017;18:347-56.

13. Vercellino L, Montravers F, de Parades V, Huchet V, Kerrou K, Bauer P, Touboul E, Talbot JN. Impact of FDG PET/CT in the staging and the follow-up of anal carcinoma. Int J Color Dis. 2011;26:201-10.

14. Benson AB 3rd, Arnoletti JP, Bekaii-Saab T, Chan E, Chen YJ, Choti MA, Cooper HS, Dilawari RA, Engstrom PF, Enzinger PC, Fakih MG, Fleshman JW Jr, Fuchs CS, Grem JL, Leong LA, Lin E, May KS, Mulcahy MF, Murphy K, Rohren E, Ryan DP, Saltz L, Sharma S, Shibata D, Skibber JM, Small W Jr, Sofocleous CT, Venook AP, Willett C, Freedman-Cass DA. National 
Comprehensive Cancer Network.. Anal carcinoma, version 2.2012: featured updates to the NCCN guidelines. J Natl Compr Cancer Netw. 2012;10:449-54.

15. Schwarz JK, Siegel BA, Dehdashti F, Myerson RJ, Fleshman JW, Grigsby PW. Tumor response and survival predicted by post-therapy FDG-PET/CT in anal cancer. Int J Radiat Oncol Biol Phys. 2008;71:180-6.

16. Saboo SS, Zukotynski K, Shinagare AB, Krajewski KM, Ramaiya N. Anal carcinoma: FDG PET/CT in staging, response evaluation, and follow-up. Abdom Imaging. 2013;38:728-35.

17. Nigro ND, Vaitkevicius VK, Considine B. Combined therapy for cancer of the anal canal: a preliminary report. Dis Colon rectum. 1974;17:354-6.

18. Faria MH, Neves Filho EH, Alves MK, Burbano RM, de Moraes Filho MO, Rabenhorst SH. TP53 mutations in astrocytic gliomas: an association with histological grade, TP53 codon 72 polymorphism and p53 expression. APMIS Acta Pathol Microbiol Immunol Scand. 2012;120:882-9.

19. Hopman AH, Ramaekers FC, Raap AK, Beck JL, Devilee P, van der Ploeg M, Vooijs GP. In situ hybridization as a tool to study numerical chromosome aberrations in solid bladder tumors. Histochemistry. 1988;89:307-16.

20. Leal MF, Calcagno DQ, Demachki S, Assumpção PP, Chammas R, Burbano RR, Smith Mde A. Clinical implication of 14-3-3 epsilon expression in gastric cancer. World J Gastroenterol. 2012;18:1531-7.

21. Salati SA, Al KA. Anal cancer - a review. Int J Health Sci. 2012;6:206-30.

22. Goh V, Gollub FK, Liaw J, Wellsted D, Przybytniak I, Padhani AR, GlynneJones R. Magnetic resonance imaging assessment of squamous cell carcinoma of the anal canal before and after chemoradiation: can mri predict for eventual clinical outcome? Int J Radiat Oncol Biol Phys. 2010;78:715-21.

23. RD J, Glynne-Jones R, Meadows HM, Cunningham D, Myint AS, Saunders MP, Maughan T, McDonald A, Essapen S, Leslie M, Falk S, Wilson C, Gollins S, Begum R, Ledermann J, Kadalayil L, Sebag-Montefiore D. Mitomycin or cisplatin chemoradiation with or without maintenance chemotherapy for treatment of squamous-cell carcinoma of the anus (ACT II): a randomised, phase 3, open-label, 2 × 2 factorial trial. Lancet Oncol. 2013;14:516-24.

24. Cardesa A, Nadal A. Carcinoma of the head and neck in the HPV era. Acta Derm Venerol Alp Pannonica Adriat. 2011;20:161-73.

25. Coutlée F, de Pokomandy A, Franco EL. Epidemiology, natural history and risk factors for anal intraepithelial neoplasia. Sex Health. 2012;9:547-55.

26. Szmulowicz UM, Wu JS. Squamous cell carcinoma of the anal canal: a review of the aetiology, presentation, staging, prognosis and methods available for treatment. Sex Health. 2012;9:593-609.

27. G E, Foo M, Harrow S, McGregor G, Hay J. Outcomes of salvage surgery for epidermoid carcinoma of the anus following failed combined modality treatment. Am J Surg. 2011;201:628-33.

28. Chapet $\mathrm{O}$, Gerard JP, Riche B, Alessio A, Mornex F, Romestaing P. Prognostic value of tumor regression evaluated after first course of radiotherapy for anal canal cancer. Int J Radiat Oncol Biol Phys. 2005;63:1316-24.

29. Poggio JL. Premalignant lesions of the anal canal and squamous cell carcinoma of the anal canal. Clin Colon Rect Surg. 2011;24:177-92.

30. Serup-Hansen E, Linnemann D, Skovrider-Ruminski W, Høgdall E, Geertsen PF, Havsteen H. Human papillomavirus genotyping and p16 expression as prognostic factors for patients with American joint committee on cancer stages I to III carcinoma of the anal canal. J Clin Oncol. 2014;32(17):1812.

31. Charlton J, Pavasovic V, Pritchard-Jones K. Biomarkers to detect Wilms tumors in pediatric patients: where are we now? Future Oncol. 2015;11:2221-34.

32. Sidow A, Spies N. Concepts in solid tumor evolution. Trends Genet. 2015;31:208-14.

33. Chen JM, Cooper DN, Chuzhanova N, Férec C, Patrinos GP. Gene conversion: mechanisms, evolution and human disease. Nat Rev Genet. 2007;8:762-75.

34. Haupt S, Raghu D, Haupt Y. Mutant p53 drives cancer by subverting multiple tumor suppression pathways. Front Oncol. 2016;6:12.

35. Boulenouar S, Weyn C, Van Noppen M, Moussa Ali M, Favre M, Delvenne PO, Bex F, Noël A, Englert Y, Fontaine V. Effects of HPV-16 E5, E6 and E7 proteins on survival, adhesion, migration and invasion of trophoblastic cells. Carcinogenesis. 2010;31:473-80.

36. WH W, Taube JM, Poeta ML, Begum S, Sidransky D, Koch WM. Inverse relationship between human papillomavirus- 16 infection and disruptive p53 gene mutations in squamous cell carcinoma of the head and neck. Clin Cancer Res. 2008;14:366-9.

37. Williams AB, Schumacher B. p53 in the DNA-Damage-Repair Process. Cold Spring Harb Perspect Med. 2016;6

38. Allal AS, Waelchli L, Prognostic BMA. Value of apoptosis-regulating protein expression in anal squamous cell carcinoma. Clin Cancer Res. 2003:9:6489-96.
39. Bonin SR, Pajak TF, Russell AH, Coia LR, Paris KJ, Flam MS, Sauter ER. Overexpression Of p53 protein and outcome of patients treated with chemoradiation for carcinoma of the anal canal: a report of randomized trial RTOG 87-04. Radiation therapy oncology group. Cancer. 1999:85:1226-33.

40. Indinnimeo M, Cicchini C, Stazi A, Giarnieri E, French D, Limiti MR, Ghini C, Vecchione A. Human Papillomavirus infection and p53 nuclear overexpression in anal canal carcinoma. J Exp Clin Cancer Res. 1999;18:47-52.

41. Tanum G, Holm R. Anal carcinoma: a clinical approach to p53 and RB gene proteins. Oncologia. 1996;53:369-73.

42. Wong CS, Tsao MS, Sharma V, Chapman WB, Pintilie M, Cummings BJ. Prognostic Role of p53 protein expression in epidermoid carcinoma of the anal canal. Int J Radiat Oncol Biol Phys. 1999;45:309-14.

43. Burd EM, Dean CL. Human Papillomavirus. Microbiol Spectr. 2016:4:4.

44. Balermpas P, Martin D, Wieland U, Rave-Fränk M, Strebhardt K, Rödel C, Fokas E, Rödel F. Human papilloma virus load and PD-1/PD-L1, CD8+ and FOXP3 in anal cancer patients treated with chemoradiotherapy: rationale for immunotherapy. Oncoimmunology. 2017;6:e1288331.

45. Martin D, Rödel F, Winkelmann R, Balermpas P, Rödel C, Fokas E. Peripheral leukocytosis is inversely correlated with Intratumoral CD8+ T-cell infiltration and associated with worse outcome after Chemoradiotherapy in anal cancer. Front Immunol. 2017:8:1225.

46. Gilbert DC, Serup-Hansen E, Linnemann D, Høgdall E, Bailey C, Summers J, Havsteen $H$, Thomas GJ. Tumour-infiltrating lymphocyte scores effectively stratify outcomes over and above p16 post chemo-radiotherapy in anal cancer. Br J Cancer. 2016;114:134-7.

\section{Submit your next manuscript to BioMed Central and we will help you at every step:}

- We accept pre-submission inquiries

- Our selector tool helps you to find the most relevant journal

- We provide round the clock customer support

- Convenient online submission

- Thorough peer review

- Inclusion in PubMed and all major indexing services

- Maximum visibility for your research

Submit your manuscript at www.biomedcentral.com/submit
C Biomed Central 